\title{
Small Group Learning in Otorhinolaryngology Using Clinical Cases in Medical Students
}

\author{
Vanita Sarin
}

\begin{abstract}
Introduction: Small group learning (SGL) promotes active involvement of learner in the entire learning cycle, well-defined task orientation with achievable specific aims and objectives in a given time and the reflection based on experience and deep learning. The main aim of this study is to determine the qualitative and quantitative effectiveness of SGL for 6th-semester MBBS students posted in the Department of Otorhinolaryngology for their clinical postings.
\end{abstract}

Materials and methods: Two sessions of SGL (SGL-1 and SGL-2) were designed and conducted for the students. A pre- and post-test of $15 \mathrm{MCQ}$ questions were used for formative assessment, before and after each SGL session. A feedback questionnaire on five points Likert scale was designed and validated and administered to the students. The data obtained from pre- and post-tests (SGL1 and 2) was statistically analyzed. Both qualitative and quantitative analysis of feedback questionnaire was also done.

Results: There was a marked improvement in the scores in the post-session test both in SGL-1and SGL-2.In SGL-1 pretest $48.86 \%$, students scored marks between the range of 6 to 10 while in the post-test about $89.9 \%$ students scored between the range of 11 to 15 . In SGL-2, $74.19 \%$ students scored marks in the range of 6 to 10 in the pretest while in the posttest $82.25 \%$ students scored in the range of 11 to 15 . In the feedback questionnaire too, students have supported that SGL had enhanced their learning, communication skills and they all were of the opinion that SGL should be recommended in other departments and should be incorporated in the curriculum.

Conclusion: Small group learning (SGL) is a profoundly effective method of teaching and learning. SGL sessions provide the productive academic environment, strategy for dynamic and collaborative learning during undergraduate training.

Keywords: Collaborative learning, Learning cycle, Selfdirected learning, Small group learning (SGL)

How to cite this article: Sarin V. Small Group Learning (SGL) in Otorhinolaryngology Using Clinical Cases in Medical Students. Curr Trends Diagn Treat 2018;2(1):54-57.

\section{Professor}

Department of Otorhinolaryngology and Head and Neck Surgery, Sri Guru Ram Das Institute of Medical Sciences and Research, Vallah, Amritsar, Punjab, India

Corresponding Author: Vanita Sarin, Professor, Department of Otorhinolaryngology and Head and Neck Surgery, Sri Guru Ram Das Institute of Medical Sciences and Research, Vallah, Amritsar, Punjab, India, e-mail: vanitasarin@yahoo.co.in

\author{
Source of support: Nil \\ Conflict of interest: None
}

\section{INTRODUCTION}

By definition, a group is a number of people interacting in a face to face situation. SGL may be defined as a group of learners demonstrating three common characteristics; active participation, a specific task, and reflection. ${ }^{1} \mathrm{SGL}$ is a process of learning that takes place when students work together in groups of 8 to 10. Small group tutorials are commonly used teaching-learning $(\mathrm{T} / \mathrm{L})$ methods in the health professions. SGL offers students an opportunity to discuss and refine their understanding of complex issues, to solve problems and apply their knowledge to new situations and to reflect on their attitudes and feelings. ${ }^{2}$ As Jason and Westbery have said, SGL can be lively, constructive interactions among students. It increases student interest, retention of knowledge, enhances the transfer of concepts to novel issues, students critical skills, teamwork ability, self-directed learning, communication skills, studentfaculty and peer-peer interaction. The most important characteristic of SGL is active involvement of learner in the entire learning cycle, well-defined task orientation with achievable specific aims and objectives in a given time and the reflection based on experience and deep learning. ${ }^{3}$ Though small group learning is a useful educational approach it is not an easy option to choose. The group work has to be carefully planned, may require the production of stimulus or resource material and frequently requires a facilitator. Also, the group function and the learning that takes place needs to be assessed and evaluated. Facilitatory skills are important and require the teacher to ensure that both the task is achieved and the group functioning is maintained. ${ }^{4}$ The group sessions are based on an experiential, self-directed approach to learning, where students take responsibility for their learning. However, common problems often arise, such as inconsistent quality, diverse approaches, and varying levels of facilitator skills. ${ }^{5}$ In spite of these challenges, the small-group teaching model has provided a successful learning/teaching experience for both students and the faculty.

The goal of this study is to highlight that SGL can be enjoyable and effective and to recommend its frequent use in the undergraduate teaching. 


\section{MATERIALS AND METHODS}

After due permission from the institutional ethics committee, the SGL exercise was introduced to the 6th-semester MBBS students. The students were oriented to SGL and written informed consent was taken for participation. The whole batch of 100 students of the 6th semester was divided into four batches of 25 students each (at a time 25 students come for clinical posting in Otorhinolaryngology). The batch of 25 students was randomly divided into three groups of 8 to 9 students each. Two topics (A and $B$ ) were selected by the facilitator for two sessions of SGL (SGL-I and SGL-2). For both the sessions of SGL those topics were selected which were already taught in the theory class in the form of a didactic lecture. A day before the allotment of the topic of SGL-1, a pretest on the topic comprising of 15 MCQ's (total marks-15) was conducted (to be answered individually). In SGL-I each group was given a short case history on the topic- A, 48 hours before the session. Each history had 3 to 4 questions about the case. Students were free to work in a group and discuss and use any resource as reference material to help them answer the questions. Duration of each SGL session was 3 hours (routine clinical posting). After that, each group of the three subgroups presented their case in front of the whole batch of 25 students; the presenter was picked up randomly by the facilitator. All the queries related to the case were answered by the presenting group, and the facilitator cleared doubts wherever necessary. At the end of the session, a post-test with 15 MCQ's (total marks 15) was given to the students (to be answered individually). The second session of SGL (SGL-2) was held similarly on the same batch of 25 students on Topic-B. This exercise was repeated with each batch during their posting in the department of otorhinolaryngology.

A structured questionnaire designed as per Likert scale with a qualitative component was administered to the students after completion of both the SGL sessions, asking them about their comments about SGL and suggestions about its further application in the present curriculum. SGL- 1 and SGL- 2 were conducted on four batches of 25 students each.

\section{Assessment}

- Pretest of Topic A vs post-test of Topic A by paired t-test (SGL-1)

- Pretest of Topic B vs post-test of Topic B by paired t-test (SGL-2)

- A structured questionnaire designed as per the Likert scale with the qualitative component. It was administered to the students after completion of the study and was analyzed.

\section{RESULTS}

In SGL-1, 88 students participated out of which 57 (64.7\%) were females while 31 were males (35.3\%). In SGL-2, 62 students participated, and the number of females and males were equal (i.e., 31 each), the reason for a decrease in the student participation was that one batch did not attend the session because of the ongoing summer vacations.

In SGL-1 (Table 1) in the pre-test, only 29 students out of $88(32.95 \%)$ secured marks lying in the range between 11 to 15 , while in the post-test this figure increased to $89.9 \%$. In the first session, $18.18 \%$ (16 out of 88 ) secured $<5$ marks while this figure was reduced to $1.1 \%$ in the post-test. The paired t-test value was $P(X 2>60.403)=0.000$ in SGL-1, which was highly significant. This indicated that SGL-1 had definitely improved the learning and understanding of the subject in the undergraduate students.

Similarly in the second session of SGL (Table 2) in the pre-test about $74.19 \%$ (46 out of 62 ) students secured marks lying in the range between 6 to 10 while in the post-test about $82.25 \%$ students secured more than 10 marks. Only two students out of 62 students (3.22\%) secured less than 6 marks. The paired t-test value was $\mathrm{P}(\mathrm{X} 2>61.607)=0.000$ which was highly significant. So

Table 1: Result of pre- and post-test of SGL-1

\begin{tabular}{llllll}
\hline & \multicolumn{2}{c}{ Pre-test } & & \multicolumn{2}{c}{ Post-test } \\
\cline { 2 - 3 } \cline { 5 - 5 } Marks obtained & No of students & Percentage & & No of students & Percentage \\
\hline $0-5$ & 16 & 18.18 & 1 & 1.1 \\
$6-10$ & 43 & 48.86 & 8 & 9 \\
$10-15$ & 29 & 32.95 & 79 & 89.9 \\
\hline
\end{tabular}

Table 2: Result of pre- and post-test of SGL-2

\begin{tabular}{llllll}
\hline & \multicolumn{2}{c}{ Pre-test } & & \multicolumn{2}{c}{ Post-test } \\
\cline { 2 - 3 } \cline { 5 - 5 } Marks obtained & No of students & Percentage & & No of students & Percentage \\
\hline $0-5$ & 8 & 12.9 & 2 & 3.22 \\
$6-10$ & 46 & 74.19 & 9 & 14.5 \\
$10-15$ & 8 & 12.9 & 51 & 82.25 \\
\hline
\end{tabular}


these post-test marks again to consolidate the fact that SGL had helped the students to achieve a higher level of knowledge.

A structured questionnaire designed as per the Likert scale with a qualitative component which was given to the students consisted of 10 feedback sentences regarding SGL. The students' response to the structured questionnaire designed as per Likert scale revealed (Graph 1) that 75\% students strongly agreed (SA) and $25 \%$ agreed (A) that SGL helped them to get a higher level of knowledge. $72.7 \%$ of students SA that the understanding of the topic was better when compared to didactic lectures and $27.27 \%$ agreed to it. $61.36 \%$ students (SA) were keen that SGL should be regularly incorporated in the curriculum. $76 \%$ of students strongly agreed that SGL reduced the time required for self-study while $69.3 \%$ strongly recommended its use in other departments too. $68.18 \%$ of students strongly agreed that SGL had increased their self-confidence. Almost all students (100\%)

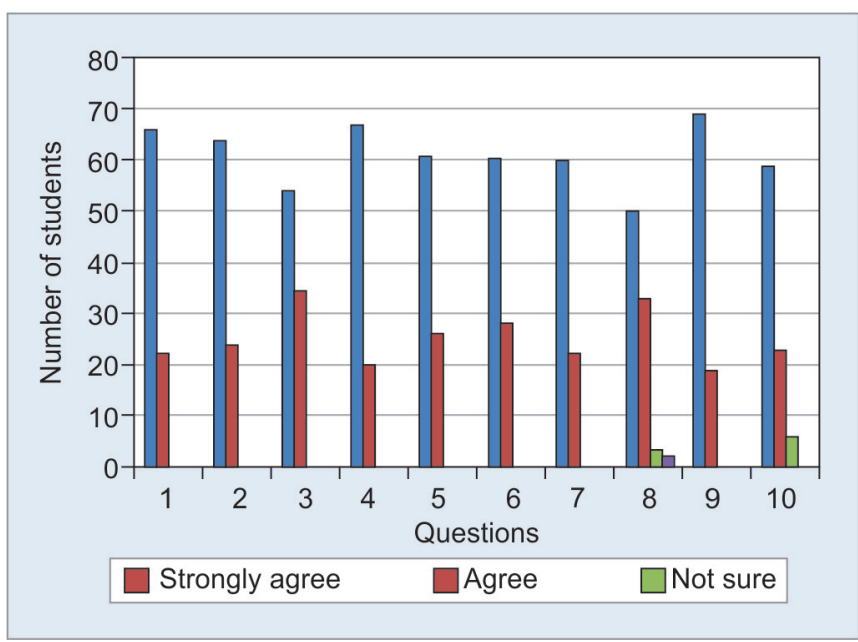

Graph 1: Result of student feedback questionnaire agreed that SGL was more effective than lectures. 93.15\% were fully satisfied with SGL. The questions given in the annexure were administered to the students after both the sessions of SGL.

\section{DISCUSSION}

SGL is an interesting issue and an educational innovation in medical education. Over the last four decades, SGL has achieved an admirable position in the medical education and is well-liked as a means for encouraging students and enhancing the process of deep learning. To achieve a better SGL environment, it is important to develop appropriate groups so that students can be actively involved throughout the learning process. 3 Like De Villiers et al. we found evidence of selfreported improvement in knowledge by the method of SGL. ${ }^{6}$ In the present study, about $92 \%$ of students reported that SGL had helped them to understand the topic better. In the quantitative analysis also there was a marked improvement in the marks obtained in the post-test in both SGL-1 and SGL-2. Gosh in a Canadian meta-analysis on continuing medical education reported that, not only the size of groups but the interactivity and the multiplicity of methods of instruction was important in learning ${ }^{7}$ and our study too about $78 \%$ students have revealed that SGL made them prepare the course material in a better way than if they had studied alone. Fryer-Edwards et al. ${ }^{8}$ found that SGL was particularly suited to complex skills such as communication when researching medical oncology teaching. In this study too about $89 \%$ of students have responded to the fact that SGL had increased their self-confidence and attitude towards learning and had enhanced the sense of belongingness. A similar study

\section{Annexure}

Student Feedback questionnaire-read the questions on SGL carefully and tick any one of the options

\begin{tabular}{|c|c|c|c|c|c|c|}
\hline No & Question & $S A$ & $A$ & $N S$ & $D$ & $S D$ \\
\hline 1 & SGL helps me to get a higher level of knowledge & & & & & \\
\hline 2 & $\begin{array}{l}\text { Understanding of the topic is better with this method as compared } \\
\text { to lectures }\end{array}$ & & & & & \\
\hline 3 & This exercise can be regularly incorporated in the curriculum & & & & & \\
\hline 4 & $\begin{array}{l}\text { SGL reduces the time needed for self study when compared to } \\
\text { lectures }\end{array}$ & & & & & \\
\hline 5 & I would like to recommend SGL to other departments & & & & & \\
\hline 6 & $\begin{array}{l}\text { Groups help me learn the course material more than if I just } \\
\text { studied alone }\end{array}$ & & & & & \\
\hline 7 & $\begin{array}{l}\text { SGL has increased my self confidence and attitude towards } \\
\text { learning }\end{array}$ & & & & & \\
\hline 8 & Working in a group has enhanced the sense of who I am & & & & & \\
\hline 9 & SGL is more effective than PBL & & & & & \\
\hline 10 & Overall I am satisfied with this SGL approach & & & & & \\
\hline
\end{tabular}

SA-strongly agree, A-agree, NS-not sure, D-disagree, SD-strongly disagree

Any other comments/suggestions: (Please feel free to express) 
done by Wilhelm et al. ${ }^{9}$ concluded that small groups learning were empowering, confidence increasing and useful for addressing psychological and interpersonal issues at work. White et al., ${ }^{10}$ Peloso and Stakiw ${ }^{11}$ in an experience-based report suggested that "key concepts and practice changes are reinforced" in group work. They also suggested that SGL was sustainable over time. Learning by its nature was unsettling and a challenging process which stimulates anxiety thus the emotional context of learning, therefore it needs to be recognized and properly addressed. P Cartney ${ }^{12}$ in his study evaluated how sensitivity to group processes and an understanding of the emotional impact of working in small groups can be utilized most effectively by the teaching staff, and this SGL approach could enhance the learning and teaching experience, promote student integration and thus progression and retention. Small-group work is a key part of academic learning, and there is a sense of identity and belonging that a student can experience in a well-run group and this should not be underestimated. ${ }^{13,14} \mathrm{~S}$ Bob et al. ${ }^{15}$ in their article stated that group work is found to be an effective means of enhancing reflective practice. Problems of engaging the whole group responsibility, for the tasks and activities can be effectively managed through the appropriate structuring of the learning experiences, induction programs in teamwork, review, tutor facilitation and proper training of how to conduct an SGL. Cress and Wilhelm ${ }^{16}$ found that, where students experience working in a socially cohesive group, the learning process is enhanced and is well retained.

So, the results of our study and review of literature of SGL undisputedly show that, for individual students, working in groups offers valuable opportunities for selfdevelopment, interpersonal growth, and support.

\section{CONCLUSION}

Hence with the results of our study and with enough literature it has been reinforced that SGL offers active participation of learners, increases the teamwork ability, retention of knowledge, enhance transfer of concepts to new problems, increases student interest and improves self-directed learning and critical skills. It develops self-motivation, exploration of issues, deep learning, high order activities and improves the communication skills.

\section{REFERENCES}

1. Jones RW. Learning and teaching in small groups: Characteristics, benefits, problems and approaches. Anaesth Intensive Care; 2007.

2. Barrows HS. The Tutorial Process (Springfield II, Southern Illinois University School of Medicine), 1998.

3. Sultan AM. Basic steps in establishing effective small group teaching sessions in medical schools. Pak J Med Sci.2013 JulAug; 29(4):1071-1076

4. J R Crosby, E A Hesketh. Small group learning.Medical teacher Mar 2004,261:16-19.

5. Muller JH. Increasing the Value of Small-group Learning. Academic Medicine [Internet]. Ovid Technologies (Wolters Kluwer Health); 2000 May;75(5):518.

6. De Villiers M, Bresick G, Mash B. The value of small group learning: an evaluation of an innovative CPD programme for primary care medical practitioners. Medical Education [Internet]. Wiley; 2003 Sep;37(9):815-821.

7. Gosh AK. Organising an effective continuous medical education session. Journal of Association of Physicians of India 2008; 56:533-538.

8. Fryer-Edwards K, Arnold RM, Baile W, Tulsky JA, Petracca F, Back A. Reflective teaching practices : an approach to teaching communication skills in a small-group setting. Acad Med 2006;81(7):638-644.

9. Wilhelm K, Peel G, Sutton V, Finch A, Sved-Williams A. Small groups for supporting GPs' professional development in mental health disease - an evaluation. Aust Fam Physician 2005;34:791-794.

10. White M, Michaud G, Pachev G, Lirenman D, Kolenc A, FitzGerald JM. Randomized trial of problem-based versus didactic seminars for disseminating Evidence based guidelines on asthma management to primary care physicians. J Cont Educ Health Prof 2004; 24(4):237-243.

11. Peloso PM, Stakiw KJ. Small-group format for continuing medical education: a report from the field. J Cont Educ Health Prof 2000; 20(1):27-32.

12. Cartney, P. Adult learning styles: implications for prac-tice teaching in social work. Social Work Education. 2000;19(6): 609-626.

13. Ashman AF, Gillies RM. An historical review of the use of groups to promote socialisation and learning. In R.M. 2013.

14. Ashman AF, Gillies RM., Co-operative learning: The social and intellectual outcomes of learning in groups London: Routledge. pp 1-19.

15. Jacques D. Teaching and Learning in Small Groups:Learning in Groups: A Handbook for Improving Group Work, Third Edition. London: Kogan 2000.

16. Spalding B, Ferguson S, Garrigan P, Stewart R. How Effective is Group Work in Enhancing Work based Learning? An evaluation of an education studies course. Journal of Further and Higher Education [Internet]. Informa UK Limited; 1999 Feb;23(1):109-115.

17. Cress U, Hesse FW. Quantitative Methods for Studying Small Groups. The International Handbook of Collaborative Learning [Internet]. Chapter 5. 